\title{
Novel Technology for the Preparation of Thermal Spray Aluminium Bronze I Nano-SiC Composite Coating
}

\author{
Hu CHENG \\ School of Mechanical Engineering, Taizhou University, Taizhou 318000, P.R. China \\ email: jxchenhu@tzc.edu.cn
}

Keywords: Aluminium bronze; Nano-SiC; Thermal spray; Composite powders; Coating

\begin{abstract}
The purpose of this study was to develop a method that may be suitable for preparing the thermal spray aluminium bronze / nano-SiC composite coating. Inhomogenous precipitation, sintering, broke and plasma spray composite technologies were used to prepare the aluminium bronze / nano-SiC composite coating. It was found that during inhomogeneous precipitation, Nano-SiC particles uniformly dispersed in $\mathrm{Cu}$ powders, $\mathrm{Cu}_{2} \mathrm{O}$ content in $\mathrm{Cu}$-coated nano-SiC powders decreases as reaction temperature increases. The suitable sintered temperature for the aluminium bronze / nano-SiC composite powders was at $1100{ }^{\circ} \mathrm{C}$. The composite coating was relatively compact although some pores were visible.
\end{abstract}

\section{Introduction}

Aluminium bronze has many excellent properties, such as good corrosion resistance, high thermal conductivity and stable inflexibility etc. [1]. When it was serviced as mold materials, scratching the parts surface can be avoided during stretch forming [2]. Fabricating aluminium bronze coatings on relatively cheap steel surface by using thermal spray technology can not only reduce the use quantity of expensive aluminium bronze, but also give full play to its excellent performances. S. Alam [3] and Z. Zhang [4] et al. successfully fabricated aluminium bronze coatings on steel by using thermal spray technology, and systematically studied the microstructure and properties of the coatings. In order to improve the wear resistance of aluminium bronze coatings, W. Li [5, 6] et al. prepared the aluminium bronze coatings with high contents of $\mathrm{Al}(14 \mathrm{wt} \%)$, it was found that harden $\mathrm{k}$ phase (such as FeAl, FeAlMn etc.) in the coatings contributed to the higher wear resistance. However, as $\mathrm{k}$ phase contents increase, the ductility of the coatings will obviously decrease.

Nano-ceramic particles (such as nano-SiC) dispersing in the metal materials can not only improve the hardness and wear resistance, but also keep the sufficient ductility of the materials [7]. Therefore, in this research, thermal spray aluminium bronze / nano-SiC composite powders and coatings were prepared, and effects of preparation technology on nano-SiC particles dispersal uniformity in aluminium bronze powders and microstructure of the composite powders were investigated systematically.

\section{Experiment Details}

The Cu-coated nano-SiC powders were prepared by inhomogeneous precipitation technology. The experimental process was presented as follows. First, the nano-SiC $(40 \mathrm{~nm})$ suspension and $\mathrm{CuSO}_{4} \cdot 5 \mathrm{H}_{2} \mathrm{O}$ water solution were prepared, respectively. Then the nano-SiC suspension was mixed into $\mathrm{CuSO}_{4} \cdot 5 \mathrm{H}_{2} \mathrm{O}$ water solution to form blend suspension. Then a certain amount of $\mathrm{Zn}$ powders were slowly added into the blend suspension, and the magnetic stirrer was running for 5 min at 200 rpm. During the magnetic stir, the reduced $\mathrm{Cu}$ from $\mathrm{CuSO}_{4}$ was coated on nano-SiC particles and formed $\mathrm{Cu}$-coated nano-SiC particles. Finally, the $\mathrm{Cu}$-coated nano-SiC particles were filtrated and dried at $80{ }^{\circ} \mathrm{C}$ for $24 \mathrm{~h}$ in vacuum drier.

The $\mathrm{Cu}$-coated nano-SiC powders were mixed to the matrix aluminium bronze powders to create powder blends containing $15 \%$ mass fraction of $\mathrm{Cu}$-coated nano-SiC, and milled in a planetary ball-miller for $2 \mathrm{~h}$ at $200 \mathrm{rpm}$. Stainless steel vials and balls were utilized as the milling media with 
a ball-to-powder mass ratio of 10:1. Alcohol was introduced as the precessing controlling agent (PCA) to aviod cold welding as well as preventing metal oxidation. Subsequently, the as-milled composite powders were bound by PVA and pressed into sheet bodies under 3-4 Mpa. Then the pressed sheet bodies were sintered for $2 \mathrm{~h}$ in a vacuum tubular furnace at $1050{ }^{\circ} \mathrm{C}, 1100{ }^{\circ} \mathrm{C}$ and $1150{ }^{\circ} \mathrm{C}$, respectively. Finally, the as-sintered sheet bodies were broke and sieved into 45 to $75 \mu \mathrm{m}$.

Choose 45 steel as the substrate materials, they were machined into rectangular bulk with the dimension of $40 \times 40 \times 10 \mathrm{~mm}$, using $40 \times 40 \mathrm{~mm}$ surface as the substrate surface. Before thermal spray, the substrate surfaces were coarsened by sandblast and degreased in acetone. The thermal spray experiment was carried out by plasma spary equipment. After thermal spray, metallographic samples were prepared using mechanical polishing procedures. Microstructure characterization of the powders and coatings was carried out by scanning electron microscope (SEM) and energy dispersive spectroscopy (EDS). Phase analysis of the powders and coatings were conducted by using a Philips PW type X-ray diffraction (XRD) (Cu K $\alpha$ radiation).

\section{Results and Discussion}

Fig. 1 showed SEM morphologies of Cu-coated SiC particles with different sizes (40nm, $0.5 \mu \mathrm{m}, 38$ $\mu \mathrm{m}$ and $74 \mu \mathrm{m}$, respectively). It can be seen that coarser SiC particles (such as $38 \mu \mathrm{m}$ and $74 \mu \mathrm{m}$ ) weren't completely coated by $\mathrm{Cu}$ (See Fig. 1(c) and (d)). This was probably because fine SiC particles easily suspended during the magnetic stir. Moreover, surface area of fine particles was larger than that of coarse particles, which can supply more nucleation energy for heterogeneous phase nucleation of $\mathrm{Cu}$. Therefore, fine $\mathrm{SiC}$ particles can be easily coated by $\mathrm{Cu}$ during the magnetic stir. In order to verify nano-SiC particles dispersal uniformity, EPMA was used and the results were shown in Fig. 2. According to Fig. 2, elements $\mathrm{Si}$ and $\mathrm{C}$ dispersed uniformly in $\mathrm{Cu}$ particles, which indicated that nano-SiC particles can be dispersed uniformly.

The water bath thermostatic device temperature was set at $10{ }^{\circ} \mathrm{C}, 30{ }^{\circ} \mathrm{C}, 50{ }^{\circ} \mathrm{C}, 70{ }^{\circ} \mathrm{C}$ and $90{ }^{\circ} \mathrm{C}$, respectively, and different $\mathrm{Cu}$-coated nano-SiC composite powders were obtained. Phase analysis of the powders were were conducted by XRD. Results indicates that phase of the powders consist of $\mathrm{SiC}, \mathrm{Cu}$ and $\mathrm{Cu}_{2} \mathrm{O}$, the strongest diffraction peak is $\mathrm{Cu}(111)$, the $\mathrm{Cu}_{2} \mathrm{O}$ diffraction peaks intensity gradually decreases as the water bath temperature rises, as shown in Fig. 3. The change of $\mathrm{Cu}_{2} \mathrm{O}$ diffraction peaks intensity can be used to qualitatively judge the change of $\mathrm{Cu}_{2} \mathrm{O}$ content in the composite powders that $\mathrm{Cu}_{2} \mathrm{O}$ content grdually decreases as the water bath temperature rises.
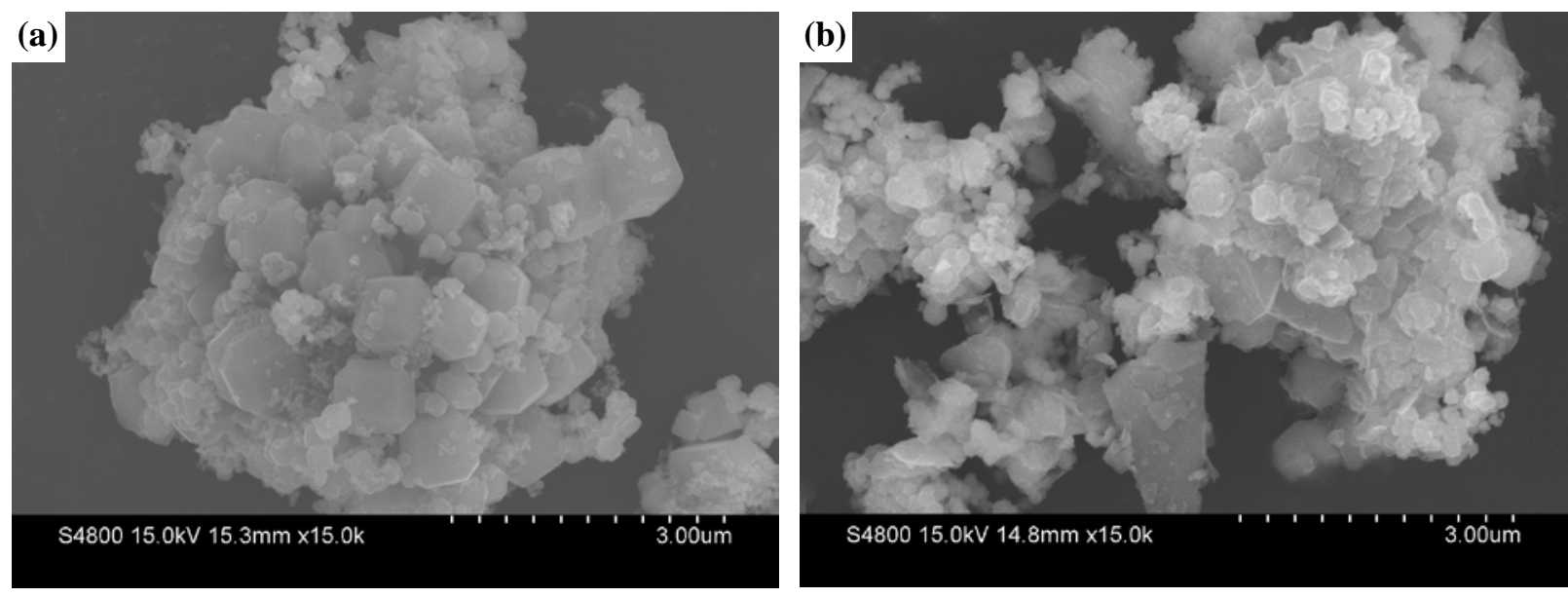

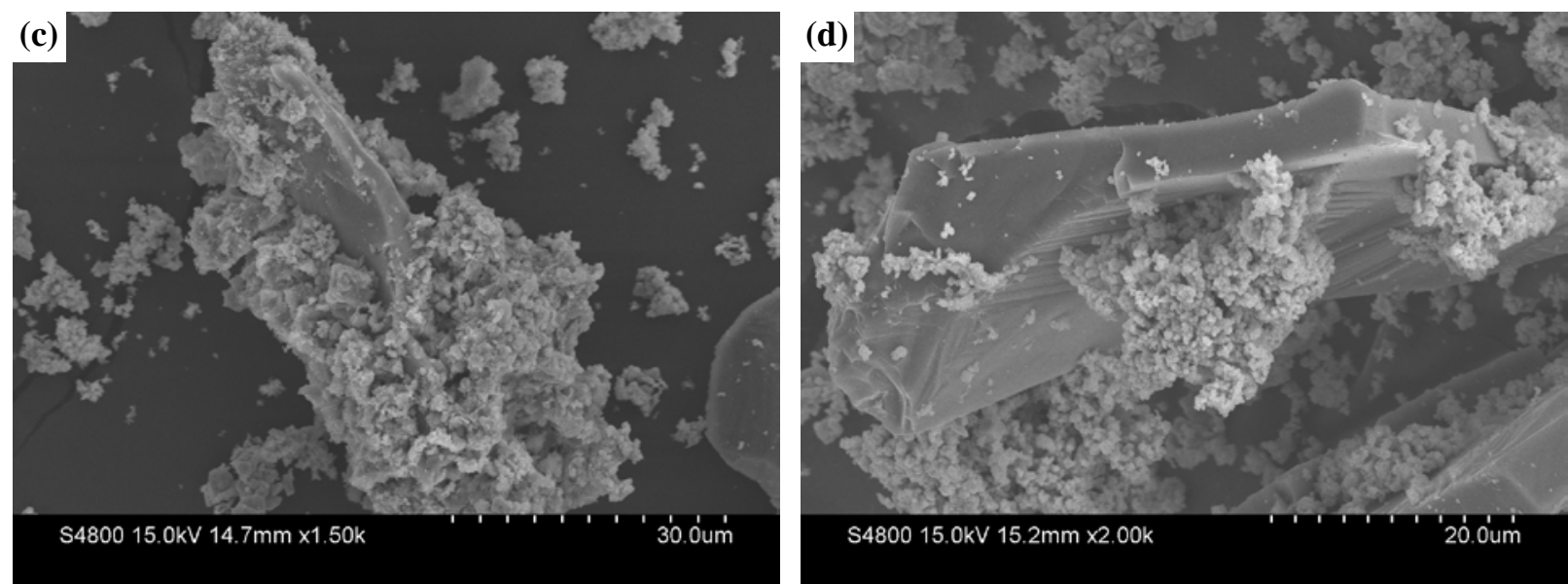

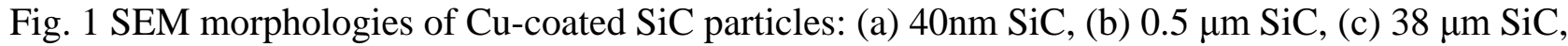
(d) $74 \mu \mathrm{m} \mathrm{SiC.}$
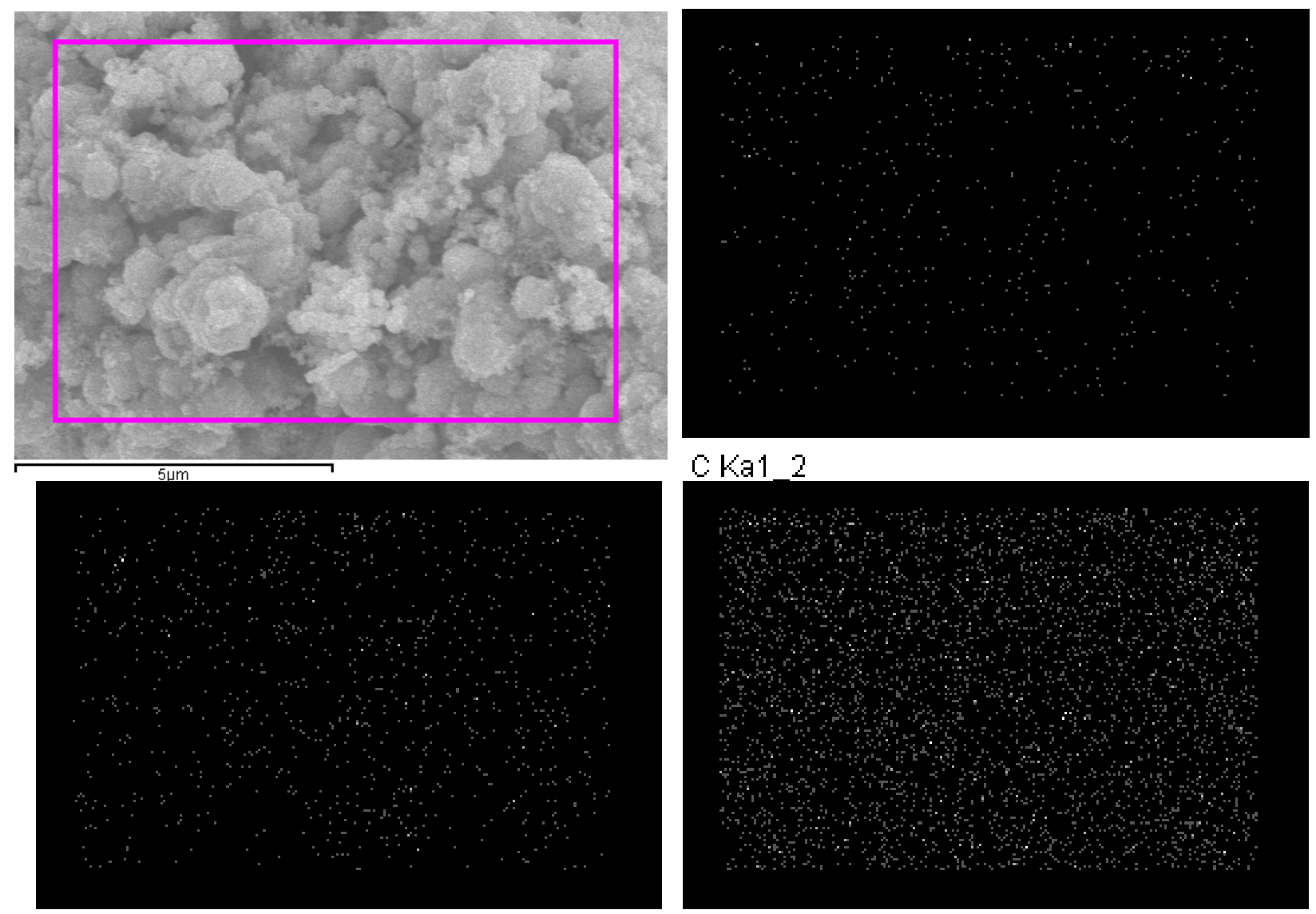

Si Ka1

Cu Ka1

Fig. 2 EPMA of $\mathrm{Cu}$-coated nano-SiC powders

The $\mathrm{Cu}_{2} \mathrm{O}$ content change was relevant to the process of $\mathrm{Cu}$ grain growth and air solubility in water solution. At lower temperature (such as $10{ }^{\circ} \mathrm{Cand} 30{ }^{\circ} \mathrm{C}$ etc.), there was more air in water solution, which led to $\mathrm{Cu}_{2} \mathrm{O}$ formation due to the reaction between fine $\mathrm{Cu}$ microcrystal and oxygen in air. With the tempetature increasing, the air content in water solution decreased, thus oxygen content also decreased, which resulted into the decrease of $\mathrm{Cu}_{2} \mathrm{O}$ content. According to Pelleg et al.'s research [8], oxidation products $\mathrm{Cu}_{2} \mathrm{O}$ on the surface of $\mathrm{Cu}$ particles can hinder the growth of $\mathrm{Cu}$ microcrystals, and prevent larger $\mathrm{Cu}$ particles formation. At higher tempetature (such as $70{ }^{\circ} \mathrm{C}$ and $90{ }^{\circ} \mathrm{C}$ etc.), as oxidation products $\mathrm{Cu}_{2} \mathrm{O}$ content decreased, the more less inhibition of $\mathrm{Cu}$ grain growth would be observed, resulting into the rapid growth of $\mathrm{Cu}$ grains and the formation of large Cu particles . 


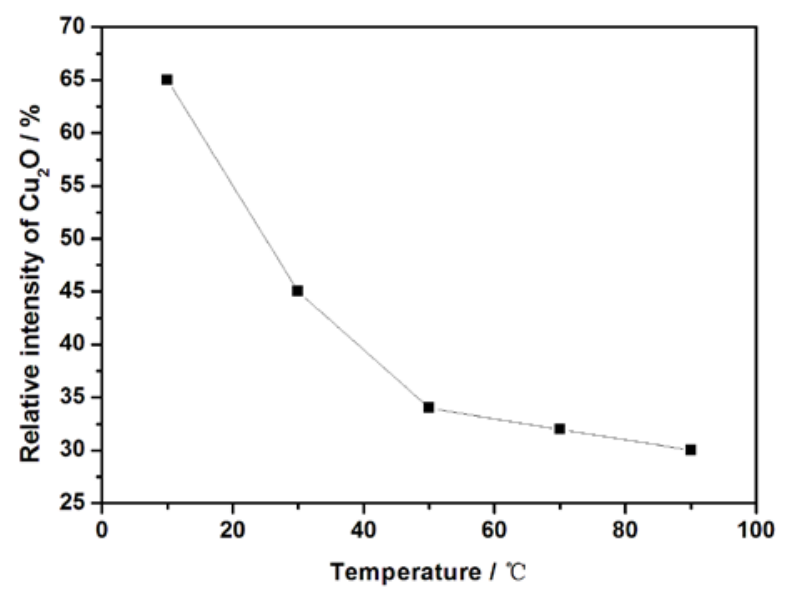

Fig. 3 Change in the relative intensity of $\mathrm{Cu}_{2} \mathrm{O}$ (111) versus temperature

Fig. 4 showed SEM morphologies of aluminium bronze powders. Aluminium bronze particles were spherical, whose particles size was $44 \sim 104 \mu \mathrm{m}$. The $\mathrm{Cu}$-coated nano-SiC and aluminium bronze composite powders were mix and milled in a planetary ball-miller for $2 \mathrm{~h}$ at $200 \mathrm{rpm}$, then the composite powders were successively dried, pressed, sintered, broke and sieved. SEM morphologies and EDS analysis of three kinds of as-sintered composite powders (at $1050{ }^{\circ} \mathrm{C}$, $1100{ }^{\circ} \mathrm{C}$ and $1150{ }^{\circ} \mathrm{C}$ ) were shown in Fig. 5. It can be seen that when the sintered temperature was at $1050{ }^{\circ} \mathrm{C}$, aluminium bronze particles weren't completely coated by Cu-coated nano-SiC particles (See Fig. 5 (a), (b) and (c)) . While when sintered tempetature at $1100{ }^{\circ} \mathrm{C}$, aluminium bronze particles were completely coated by nano-SiC particles (See Fig. 5 (d)). As sintered temperature rised to $1150{ }^{\circ} \mathrm{C}$, the coated effect of aluminium bronze was the same to that at $1100{ }^{\circ} \mathrm{C}$. However, some aluminium bronze particles bond each other in the composite powders at $1150{ }^{\circ} \mathrm{C}$ sintering temperature (See Fig. 5(e) and (f)). Obviously, this was not benefit for thermal spray. Therefore, the suitable sintered temperature for the aluminium bronze and nano-SiC composite powders was at $1100{ }^{\circ} \mathrm{C}$.

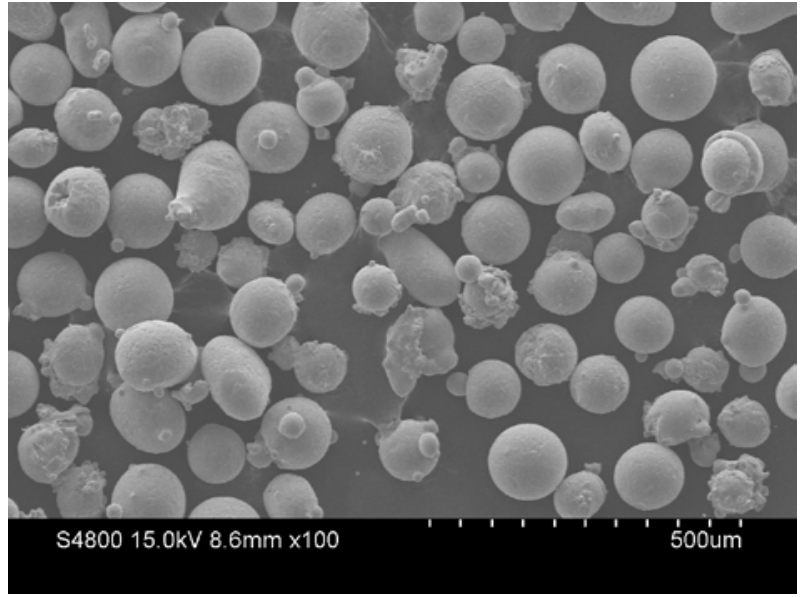

(a) low magnification

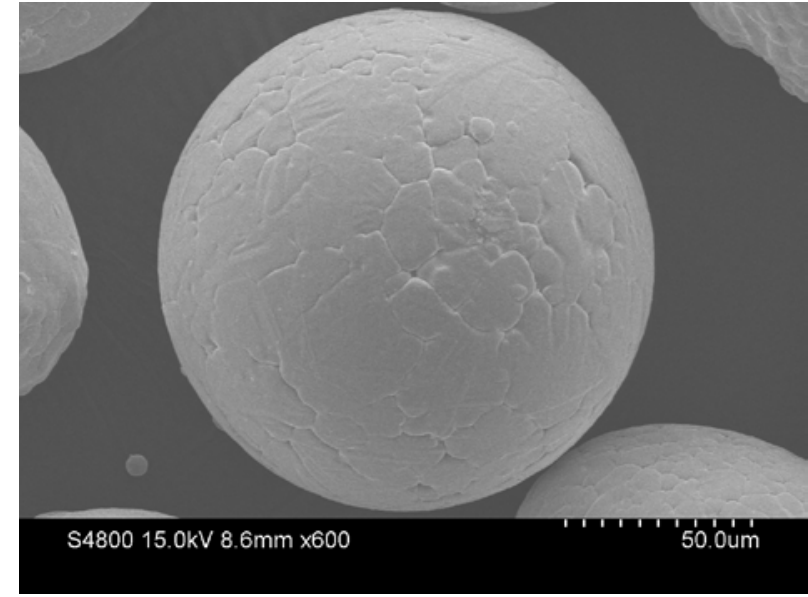

(b) high magnification

Fig. 4 SEM morphologies of aluminium bronze powders

The aluminium bronze / nano-SiC composite coating was fabricated on 45 steel by plasma spray technology. Fig. 6 showed cross-section SEM morphologies and EDS analysis of the composite coating. There was a good mechanical bonding between the composite coating and the steel substrate (See Fig. 6 (a)). The coating presented typical layer-like microstructure, moreover, the coating was relatively compact although some pores were visible. EDS analysis showed that some nano-SiC particles agglomerated in the pore regions (See Fig. 6 (b) and (c)), which indicated that nano-SiC particles non-uniformly disperse in the aluminium bronze. Therefore, this experiment technology for aluminium bronze / nano-SiC composite coating needed deeper research. In addition, $\mathrm{Al}_{2} \mathrm{O}_{3}$ particles were found in the coating (See Fig. 6 (b) and (d)). This is probably because some Al elements in aluminium bronze powders were oxygenated during plasma spray. 

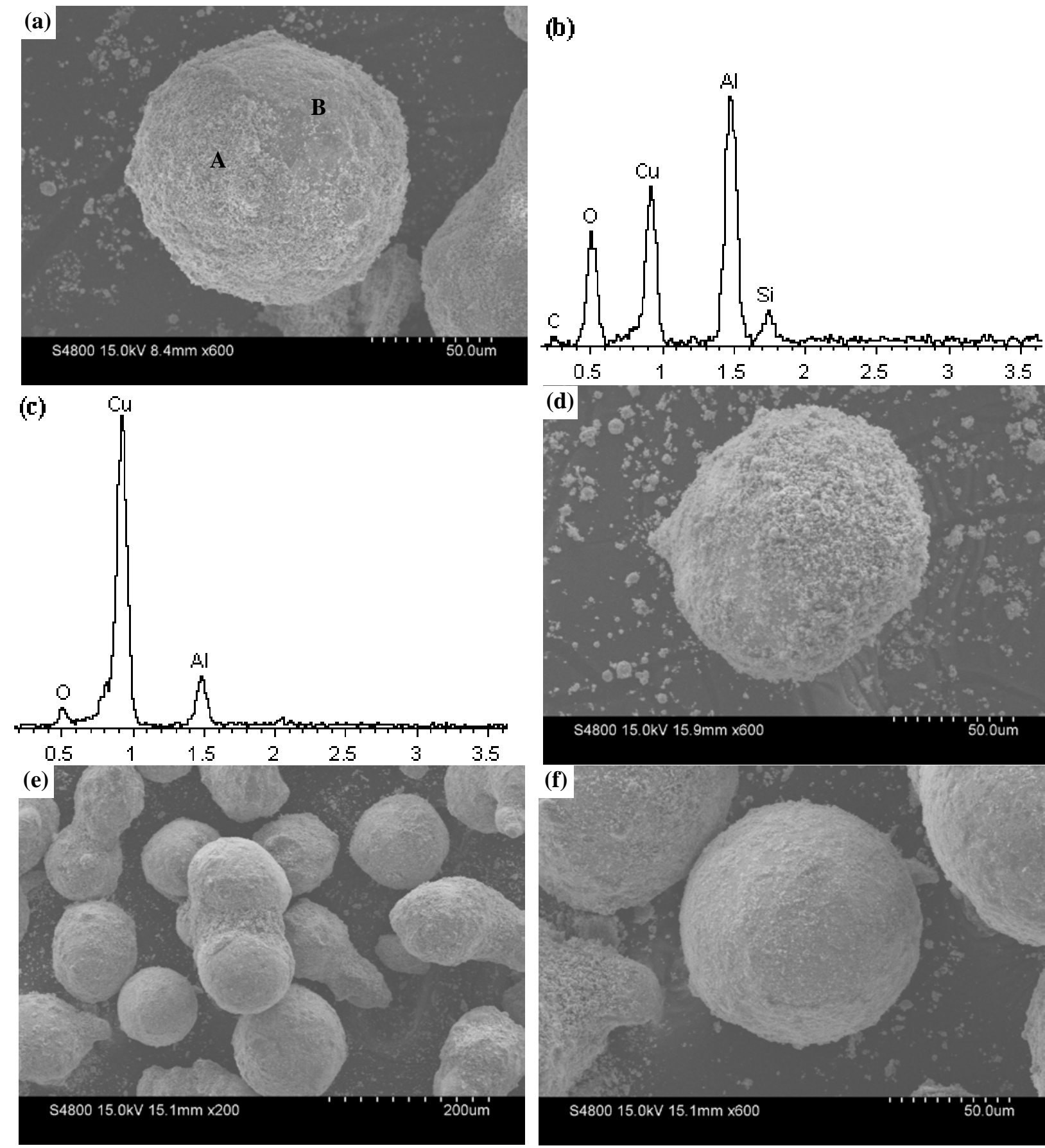

Fig. 5 SEM morphologies and EDS analysis of as-sintered composite powders under different sintered temperatures: (a) $1050{ }^{\circ} \mathrm{C}$; (b) A regions in (a); (c) B regions in (a); (d) $1100{ }^{\circ} \mathrm{C}$; (e) and (f)

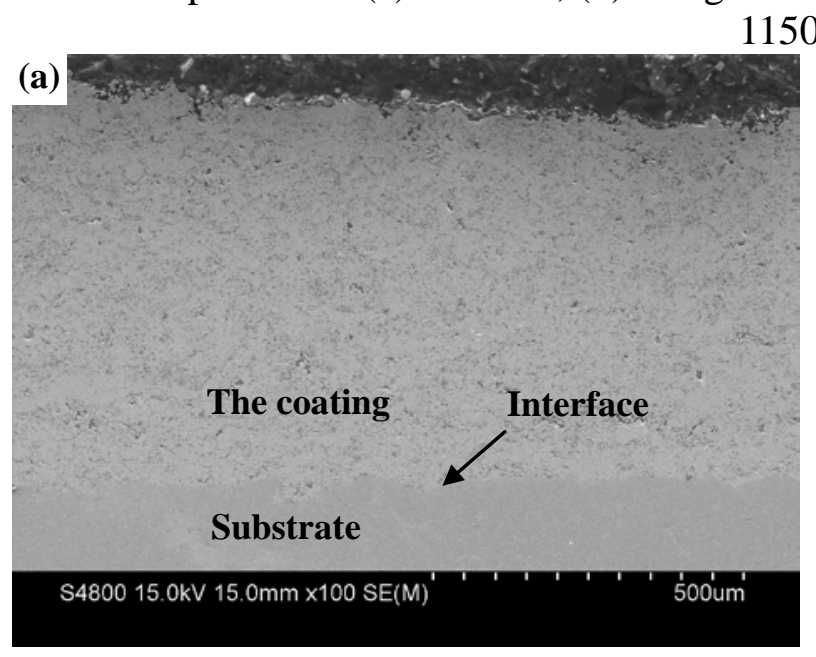

(b) 
(c)

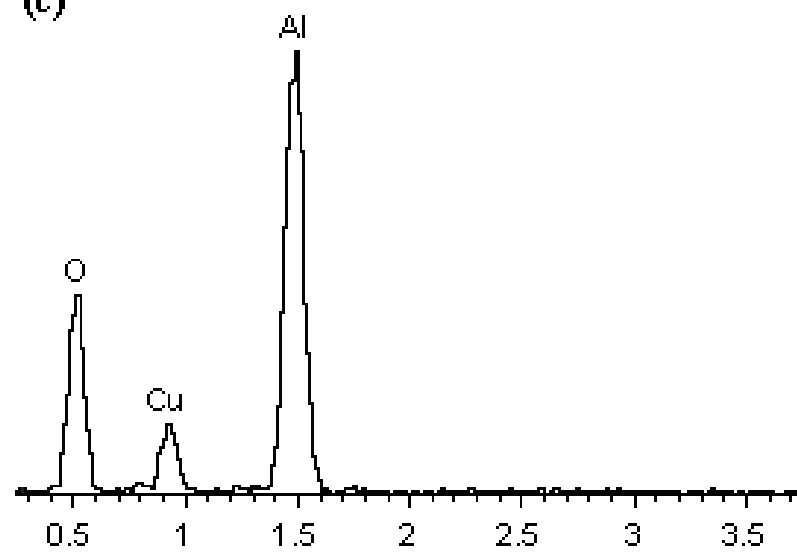

(d)

Fig. 6 Cross-section SEM morphologies and EDS analysis of the aluminium bronze / nano-SiC composite coating: (a) low magnification; (b) high magnification; (c) A regions in (a); (d) B regions in (a).

\section{Conclusion}

The Cu-coated nano-SiC powders were successfully prepared by inhomogeneous precipitation technology. Nano-SiC particles uniformly dispersed in $\mathrm{Cu}$ powders. During inhomogeneous precipitation, oxygen content in water solution decreases, which lead to the decrease of $\mathrm{Cu}_{2} \mathrm{O}$ content, as the tempetature increases. The sintered and broke technology was used to prepare alumimium bronze / nano-SiC composite powders. The suitable sintered temperature for the composite powders was at $1100{ }^{\circ} \mathrm{C}$. Finally, the alumimium bronze / nano-SiC composite coating was successfully fabricated on 45 steel by plasma spray. The coating was relatively compact although some pores were visible.

\section{Acknowledgement}

This project was supported by the public technology applied research projects of Zhejiang Province (Grant No. 2013C31117).

\section{References}

[1] Sadayappan M, Zavadil R, Sakoo M. Mechanical properties of aluminum bronze alloy C95400 [J]. AFS Transactions, 2001, 109: 745-758.

[2] Li Wensheng, Wang Zhiping, Lu Yang, et al. Review of high strength copper-based alloy on application and research [J]. Nonferrous Metals，2002， 54( 2) : 30-34. (In Chinese)

[3] S. Alam, S. Sasaki, H. Shimura. Friction and wear characteristics of aluminium bronze coatings on steel substrates sprayed by a low pressure plasma technique [J]. Wear, 2001, 248: 75-81.

[4] Z. L. Zhang, D. Y. Li, S. Y. Wang. High temperature performance of arc-sprayed aluminium bronze coatings for steel [J]. Trans. Nonferrous Met. Soc. China, 2006, 16: 868-872. (In Chinese) [5] Li Wensheng, Wang Zhiping, Lu Yang, et al. Mechanical and tribological properties of a novel aluminum bronze material for drawing dies [J]. Wear, 2006, 261(2): 155-163.

[6] Lu Yang, Li Wensheng, Wang Zhiping, at al. New developed aluminum bronze alloy for die [J]. Hot Working Technology, 2002 (3) : 45-46. (In Chinese)

[7] Y.C. Zhu, Y.K. Ken, C.X. Ding. Tribological properties of nano-structured and conventional WC-Co coatings deposited by plasma spraying, Thin Solid Films, 2001, 388(1): 277-282.

[8] J. Pelleg, M. Ruhr and M. Ganor, Control of the reaction at the fibre-matrix interface in a $\mathrm{Cu} / \mathrm{SiC}$ metal matrix composite by modifying the matrix with $2.5 \mathrm{wt} \% \mathrm{Fe}$, Mater, Sci, Egn. A, 1996, 212: 139-148. 